\title{
Kecenderungan Gangguan Perilaku pada Anak dengan Sindrom Nefrotik
}

\author{
Diarum Puspasari, ${ }^{*}$ Indria Laksmi Gamayanti, ${ }^{* *}$ Madarina Julia* \\ Bagian Ilmu Kesehatan Anak Fakultas Kedokteran Universitas Gadjah Mada/RSUP Dr Sardjito, Yogyakarta
}

Latar belakang. Sindrom nefrotik (SN) merupakan suatu penyakit kronis yang memiliki tingkat kekambuhan tinggi sehingga rentan mengalami gangguan perilaku.

Tujuan. Menilai perbedaan prevalensi gangguan perilaku pada anak dengan SN dibandingkan anak dengan penyakit kronis lainnya, baik yang mendapatkan terapi steroid maupun tidak.

Metode. Penelitian potong lintang yang melibatkan 33 anak pasien SN, 33 anak penyakit kronis dengan terapi steroid (KrS), dan 33 anak penyakit kronis tanpa terapi steroid (KrNS) usia 3-16 tahun di RSUP Dr Sardjito, Yogyakarta. Deteksi gangguan perilaku diukur menggunakan instrumen strength and difficulty questionnair (SDQ).

Hasil. Prevalensi gangguan perilaku dan peer problems lebih banyak pada SN (36,4\% dan 27,3\%) dibandingkan $\mathrm{KrS}(9,1 \%$ dan 9,1\%) dan $\operatorname{KrNS}(3 \%$ dan 3\%). Dosis kumulatif steroid tinggi (OR 11,64; IK95\% 2,33-58,06; p=0,003), frekuensi mondok lebih 2 kali (OR 10,08; IK95\% 1,7-59,65; p=0,01) dan usia muda (OR 22,87; IK95\% 1,9-274,71; p=0,01) merupakan faktor risiko terjadi gangguan perilaku. Faktor risiko peer problems adalah menderita SN (OR 12; IK95\% 1,42-101,2; p=0,02) dan frekuensi mondok lebih dari 2 kali (OR 4,9; IK95\% 1,31-18,24; p=0,01).

Kesimpulan. Prevalensi gangguan perilaku dan peer problems ditemukan lebih banyak pada SN dibanding penyakit kronis lain, tetapi gangguan tersebut lebih dipengaruhi oleh dosis kumulatif steroid tinggi, frekuensi rawat lebih dari 2 kali, dan usia muda dibandingkan dengan penyakitnya. Sari Pediatri 2015;17(1):1-8.

Kata kunci: sindrom nefrotik, gangguan perilaku, SDQ

\section{Behavioral Problems Trends in Children with Nephrotic Syndrome}

\author{
Diarum Puspasari, ${ }^{*}$ Indria Laksmi Gamayanti, ${ }^{* *}$ Madarina Julia**
}

Background. Nephrotic syndrome (NS) is a chronic disease that has high relaps rate and is often associated with behavioral problems.

Objective. To determine the prevalence of behavioral problems in children with NS in comparison to children with other chronic diseases, wih and without steroid therapy.

Methods. A cross sectional study involving 33 children with NS, 33 children with chronic diseases with steroid therapy (CrDS), and 33 children with chronic diseases without steroid therapy (CrDNS) aged 3-16 years, in Dr Sardjito hospital Yogyakarta. The behavioral problems were measured using Strength and Difficulties Questionnaire (SDQ) instrument.

Results. The prevalence of behavioral problems and peer problems in NS (36.4\% and $27.3 \%)$ was found to be significantly higher than those with $\mathrm{CrS}(9.1 \%$ and $9.1 \%)$ and CrNS (3\% and 3\%). High cumulative dose of steroid (OR 11.64; $95 \%$ CI 2.33 to 58.06; $\mathrm{p}=0.003$ ), frequency of hospitalizations for more than 2 periods (OR $10.08 ; 95 \%$ CI 1.7 to $59.65 ; \mathrm{p}=0.01$ ) and younger age (OR 22.87; 95\% CI 1.9 to 274.71; $\mathrm{p}=0.01$ ) are risk factors for behavioral problems development. Risk factors for peer problems include suffering NS disease (OR 12; 95\% CI 1.42 to 101.2; $\mathrm{p}=0.02$ ) and the frequency of hospitalizations, more than 2 times (OR 4.9; $95 \%$ CI 1.31 to 18,$24 ; \mathrm{p}=0.01$ ).

Conclusion. The prevalence of behavioral problems and peer problems are more common in children with NS compare to other children with chronic diseases. However, such disorders are more likely to be influenced by the high cumulative dose of steroid, frequency of hospitalizations more than 2 periods, and younger age, compared to the disease itself.

Sari Pediatri 2015;17(1):1-8.

Keywords: nephrotic syndrome, behavioral problem, SDQ

Alamat korespondensi: Dr. Diarum Puspasari. Bagian Ilmu Kesehatan Anak FK UGM/RSUP. Dr. Sardjito Yogyakarta, Jalan Kesehatan no 1 Sekip Yogyakarta 55284, Indonesia. Telepon. (0274) 561616, Fax. (0274) 583745. E-mail: diarumpuspasari@yahoo.co.id. 


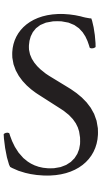
indrom nefrotik (SN) merupakan salah satu kelainan glomerular pada anak yang paling sering ditemukan. Di Indonesia dilaporkan 6 per 100.000 per tahun pada anak berusia kurang dari 14 tahun menderita SN. ${ }^{1,2}$

Penyakit kronis berdampak pada gangguan perilaku dan kehidupan sosial, seperti pada anak dengan sindrom nefrotik. Risiko psikopatologis meningkat 2,5 kali pada anak dengan kondisi kelainan kronis dibandingkan anak pada umumnya. Apabila gangguan ini tidak ditangani sejak dini, dapat menjadi lebih serius dibandingkan dengan penyakit yang dideritanya. Meskipun telah dilakukan beberapa penelitian mengenai gangguan perilaku pada anak dengan $\mathrm{SN}$, masih sulit membedakan serta mengetahui mekanisme apakah gangguan ini disebabkan oleh efek penyakit itu sendiri atau kondisi kronis atau efek dari terapi yang telah diberikan karena pengobatan pada SN ini tidak dapat dilepaskan dari pemberian steroid. Bahkan, pada terapi inisial $\mathrm{SN}$ atau pada pengobatan episode pertama SN dengan menggunakan steroid dosis tinggi, sering sudah didapatkan kelainan berupa gangguan perilaku dan menarik diri dari kehidupan sosial. ${ }^{3-5}$

Strenght and difficulties questionnaire (SDQ) merupakan instrumen pengukuran untuk melakukan deteksi terhadap gangguan perilaku yang terdiri atas 25 item pertanyaan psikologi meliputi 5 bagian, yaitu masalah emosi, perilaku, hiperaktivitas atau inatensi, masalah hubungan antar teman sebaya, dan perilaku sosial. Penggunaan instrumen ini ringkas untuk dilakukan dan lebih singkat dalam mendeteksi adanya gangguan internalisasi dan gangguan eksternalisasi. ${ }^{6}$

Tujuan dari penelitian ini untuk mengetahui prevalensi gangguan perilaku pada sindrom nefrotik serta mengidentifikasi faktor risiko yang mempengaruhi.

\section{Metode}

Penelitian rancangan potong lintang dilakukan pada bulan September sampai dengan November 2014. Kelompok sampel adalah anak usia 3 sampai 16 tahun yang telah terdiagnosis $\mathrm{SN}$ sesuai dengan kriteria diagnosis oleh ISKDC (international study of kidney disease in children). ${ }^{7}$ Sebagai kelompok pembanding adalah anak dengan penyakit kronis non sindrom nefrotik tanpa terapi steroid ( $\mathrm{KrNS}$ ) atau dengan terapi steroid (KrS). Pengambilan sampel dilakukan secara consecutive sampling dengan jumlah 33 anak pada kelompok SN sebagai kontrol, 33 kelompok KrS dan 33 kelompok KrNS sebagai pembanding. Subyek dieksklusi jika anak memiliki cacat fisik dan mental, terdiagnosis gangguan pemusatan perhatian dan hiperaktifitas (GPPH), autisme atau gangguan psikiatri lain dan tercatat dalam rekam medis sebelumnya.

Gangguan perilaku diukur dengan menggunakan instrumen strenghts and difficulties questionnaire (SDQ). Terdapat lima aspek gangguan perilaku yang dilakukan penilaian, yaitu gangguan hiperaktivitas, gangguan emosi, conduct problems, prososial, dan gangguan hubungan dengan teman sebaya atau peer problems. Faktor yang dinilai memengaruhi gangguan perilaku, meliputi penyakit SN, kelompok usia, jenis kelamin, pendidikan ibu, sosial ekonomi, usia onset penyakit, durasi sakit, dosis kumulatif steroid, frekuensi, dan durasi mondok.

Analisis bivariat dilakukan untuk menguji hubungan gangguan perilaku pada kelompok SN, $\mathrm{KrS}$, dan KrNS dalam skala kategorik menggunakan analisis chi-square dengan alternatif uji Fisher atau uji Kolmogorov-Smirnov jika tidak memenuhi syarat uji chi-square. Data numerik dianalisis menggunakan uji One way Anova atau tes Kruskal-Wallis apabila distribusi angka tidak normal. Analisis multivariat menggunakan regresi logistik untuk menilai kekuatan hubungan antara berbagai variabel yang mempunyai nilai $\mathrm{p}<0,25$ pada analisis bivariat terhadap gangguan perilaku pada kelompok SN, KrS, dan KrNS. Tingkat kemaknaan yang dipakai yaitu jika nilai $\mathrm{p}<0,05$ dan pengolahan data dengan menggunakan program SPSS (statistical package for the social science) 17. Penelitian ini telah mendapatkan persetujuan dari Komisi Etika Penelitian Fakultas Kedokteran (KEPK) Fakultas Kedokteran Universitas Gadjah Mada.

\section{Hasil}

Penelitian ini melibatkan 99 subjek, terdiri atas 33 anak pada masing-masing kelompok. Didapatkan rerata \pm SD usia ketiga kelompok tersebut $8,30 \pm 3,75$ tahun dengan usia terendah 3 tahun dan tertinggi 16 tahun. Karakteristik dasar pada kelompok kasus SN rerata ${ }_{ \pm} \mathrm{SD}$ usia onset atau awal terdiagnosis $\mathrm{SN} 5,0 \pm 3,19$ tahun dengan serta rerata \pm SD durasi menderita penyakit selama $36,1 \pm 25,4$ bulan dan dengan rerata ${ }_{ \pm} \mathrm{SD}$ dosis kumulatif steroid yang telah dikonsumsi $9335,03 \pm 4962,8 \mathrm{mg}$. 
Tabel 1. Karakteristik subyek penelitian

\begin{tabular}{|c|c|c|c|c|}
\hline Variabel & $\begin{array}{c}\text { Sindrom nefrotik/ } \\
\text { SN } \\
\text { N }(\%)\end{array}$ & $\begin{array}{c}\text { Penyakit kronis steroid/ } \\
\text { KrS } \\
\mathrm{N}(\%)\end{array}$ & $\begin{array}{c}\text { Penyakit kronis non steroid/ } \\
\text { KrNS } \\
\text { N }(\%)\end{array}$ & $\mathrm{p}$ \\
\hline $\mathrm{N}$ & 33 & 33 & 33 & \\
\hline Usia (rerata $\pm S D$, tahun) & $8,0_{ \pm} 3,75$ & $8,24 \pm 3,70$ & $8,6 \pm 3,90$ & $0,76^{* * *}$ \\
\hline $3-10$ & $24(72,7)$ & $25(75,8)$ & $20(60,6)$ & $0,36^{*}$ \\
\hline $11-16$ & $9(27,3)$ & $8(24,2)$ & $13(39,4)$ & \\
\hline \multicolumn{5}{|l|}{ Jenis kelamin } \\
\hline Perempuan & $6(18,2)$ & $13(39,4)$ & $21(63,6)$ & $0,001^{*}$ \\
\hline Laki-laki & $27(81,8)$ & $20(60,6)$ & $12(36,4)$ & \\
\hline \multicolumn{5}{|l|}{ Pendidikan ibu } \\
\hline Rendah & $20(60,6)$ & $8(24,2)$ & $17(51,5)$ & $0,009^{*}$ \\
\hline Tinggi & $13(39,4)$ & $25(75,8)$ & $16(48,5)$ & \\
\hline Usia ibu (rerata $\pm S D$, tahun) & $37 \pm 7,80$ & $37,6 \pm 5,81$ & $38,3 \pm 7,03$ & $0,77^{* *}$ \\
\hline \multicolumn{5}{|l|}{ Sosial ekonomi } \\
\hline Rendah & $13(39,4)$ & $7(21,2)$ & $12(36,4)$ & $0,23^{*}$ \\
\hline Menengah-tinggi & $20(60,6)$ & $26(78,8)$ & $21(63,6)$ & \\
\hline Durasi sakit(rerata $\pm S D$, tahun) & $36,18 \pm 25,49$ & $46,73 \pm 44,98$ & $90,67 \pm 53,2$ & $0,001^{* * *}$ \\
\hline
\end{tabular}

Keterangan: p dianggap bermakna apabila nilai $\mathrm{p}<0,05$, " chi square, " One way Anova, ${ }^{\prime \prime}$ Kruskal-Wallis

Tabel 2. Analisis bivariat penilaian SDQ antara kelompok SN, KrS, dan KrNS

\begin{tabular}{|c|c|c|c|c|}
\hline Variabel & $\begin{array}{c}\text { Sindrom nefrotik/ } \\
\text { SN } \\
\mathrm{N}=33(\%)\end{array}$ & $\begin{array}{c}\text { Penyakit kronis steroid/ } \\
\text { KrS } \\
\mathrm{N}=33(\%)\end{array}$ & $\begin{array}{c}\text { Penyakit kronis non steroid/ } \\
\text { KrNS } \\
\mathrm{N}=33(\%)\end{array}$ & $\mathrm{p}$ \\
\hline \multicolumn{5}{|c|}{ Skor gangguan perilaku total } \\
\hline Abnormal & $12(36,4)$ & $3(9,1)$ & $1(3,0)$ & $0,001^{*}$ \\
\hline Normal & $21(63,6)$ & $30(90,9)$ & $32(97,0)$ & \\
\hline \multicolumn{5}{|l|}{ Skor hiperaktif } \\
\hline Abnormal & $7(21,2)$ & $2(6,1)$ & $2(6,1)$ & $0,20^{* *}$ \\
\hline Normal & $26(78,8)$ & $31(93,9)$ & $31(93,9)$ & \\
\hline \multicolumn{5}{|c|}{ Skor conduct problem } \\
\hline Abnormal & $6(18,2)$ & $7(21,2)$ & $2(6,1)$ & $0,19^{*}$ \\
\hline Normal & $27(81,8)$ & $26(78,8)$ & $31(93,9)$ & \\
\hline \multicolumn{5}{|l|}{ Skor emosi } \\
\hline Abnormal & $8(24,2)$ & $10(30,3)$ & $7(21,2)$ & $0,68^{*}$ \\
\hline Normal & $25(75,8)$ & $23(69,7)$ & $26(78,8)$ & \\
\hline \multicolumn{5}{|c|}{ Skor peer problems } \\
\hline Abnormal & $9(27,3)$ & $3(9,1)$ & $1(3,0)$ & $0,04^{* *}$ \\
\hline Normal & $24(72,7)$ & $30(90,9)$ & $32(97,0)$ & \\
\hline \multicolumn{5}{|l|}{ Skor prososial } \\
\hline Abnormal & $2(2,0)$ & $2(2,0)$ & $0(0)$ & $0,74^{* *}$ \\
\hline Normal & $31(98,0)$ & $31(98,0)$ & $33(100)$ & \\
\hline
\end{tabular}

Keterangan: p dianggap bermakna apabila nilai $\mathrm{p}<0,05,{ }^{*}$ chi square, ${ }^{* *}$ Kolmogorov-Smirnov 
Tabel 3. Analisis bivariat faktor yang berpengaruh pada kejadian gangguan perilaku kelompok SN, KrS, dan $\mathrm{KrNS}$

\begin{tabular}{|c|c|c|c|c|c|}
\hline \multirow[b]{2}{*}{ Variabel } & \multicolumn{2}{|c|}{ Gangguan perilaku } & \multirow[b]{2}{*}{$\mathrm{RP}$} & \multirow[b]{2}{*}{ IK95\% } & \multirow[b]{2}{*}{$\mathrm{p}$} \\
\hline & $\begin{array}{c}\mathrm{Ya} \\
\mathrm{N}=99(\%)\end{array}$ & $\begin{array}{c}\text { Tidak } \\
\text { N=99(\%) }\end{array}$ & & & \\
\hline \multicolumn{6}{|l|}{ Usia } \\
\hline 3-10 tahun(anak) & $14(14,1)$ & $55(55,6)$ & 3,56 & $0,76-16,78$ & $0,13^{\mathrm{b} *}$ \\
\hline 11-16 tahun(remaja) & $2(2)$ & $28(28,3)$ & & & \\
\hline \multicolumn{6}{|l|}{ Jenis kelamin } \\
\hline Laki-laki & $15(15,2)$ & $44(44,4)$ & 13,29 & $1,68-105,3$ & $0,01^{a *}$ \\
\hline Perempuan & $1(1)$ & $39(39,4)$ & & & \\
\hline \multicolumn{6}{|l|}{ Pendidikan ibu } \\
\hline Rendah & $8(8,1)$ & $37(37,4)$ & 1,24 & $0,42-3,62$ & $0,69^{\mathrm{a}}$ \\
\hline Tinggi & $8(8,1)$ & $46(46,4)$ & & & \\
\hline \multicolumn{6}{|l|}{ Sosial ekonomi } \\
\hline Rendah & $4(4)$ & $28(28,3)$ & 0,65 & $0,19-2,21$ & $0,49^{\mathrm{a}}$ \\
\hline Menengah-ke atas & $12(12,1)$ & $55(55,6)$ & & & \\
\hline \multicolumn{6}{|l|}{ Usia onset (tahun) } \\
\hline$<3$ & $7(7,0)$ & $26(26,3)$ & 1,70 & $0,57-5,07$ & $0,33^{\mathrm{a}}$ \\
\hline$\geq 3$ & $9(9,1)$ & $57(57,6)$ & & & \\
\hline \multicolumn{6}{|l|}{ Durasi sakit (tahun) } \\
\hline$\geq 3$ & $9(9,1)$ & $44(44,4)$ & 1,14 & $0,38-3,34$ & $0,81^{\mathrm{a}}$ \\
\hline$<3$ & $7(7,1)$ & $39(39,4)$ & & & \\
\hline \multicolumn{6}{|l|}{ Frekuensi rawat (kali) } \\
\hline$>2$ & $8(8,1)$ & $14(14,1)$ & 4,92 & $1,58-15,34$ & $0,07^{\mathrm{b} *}$ \\
\hline$\leq 2$ & $8(8,1)$ & $69(69,7)$ & & & \\
\hline \multicolumn{6}{|l|}{ Durasi rawat (hari) } \\
\hline$>14$ & $10(10,1)$ & $31(31,3)$ & 2,79 & $0,92-8,44$ & $0,06^{a *}$ \\
\hline$\leq 14$ & $6(6,1)$ & $52(52,5)$ & & & \\
\hline
\end{tabular}

Keterangan: $\mathrm{p}$ dianggap bermakna apabila nilai $\mathrm{p}<0,05,{ }^{\mathrm{a}}$ chi square, ${ }^{\mathrm{b}}$ uji Fisher, ${ }^{*} \mathrm{p}<0,25$

Karakteristik subjek penelitian menunjukkan tidak didapatkan perbedaan yang bermakna pada karakteristik usia subjek, usia ibu dan status sosial ekonomi, sedangkan perbedaan bermakna didapatkan pada jenis kelamin, pendidikan ibu dan durasi sakit (Tabel 1).

Hasil analisis bivariat didapatkan perbandingan prevalensi gangguan perilaku pada kelompok $\mathrm{SN}, \mathrm{KrS}$, dan KrNS berturut-turut adalah 36,4\%, 9,1\%, dan $3 \%$. Sementara perbandingan prevalensi peer problems pada ketiga ketiga kelompok tersebut diperoleh $27,3 \%, 9,1 \%$, dan 3,\%. Prevalensi gangguan perilaku dan peer problems secara bermakna didapatkan lebih banyak pada kelompok $\mathrm{SN}$ dengan nilai $\mathrm{p}=0,001 \mathrm{dan}$ $\mathrm{p}=0,04$. Prevalensi hiperaktif pada ketiga kelompok $\mathrm{SN}, \mathrm{KrS}$, dan KrNS berturut-turut adalah 21,2\%, $6,1 \%$, dan $6,1 \%$, tetapi perbedaan tersebut secara statistik tak bermakna karena memiliki nilai $\mathrm{p}=0,20$ (Tabel 2).

Pada Tabel 3 didapatkan faktor yang secara bermakna memengaruhi gangguan perilaku pada ketiga kelompok adalah jenis kelamin. Selain itu, faktor yang memiliki nilai $\mathrm{p}<0,25$ tetap dilakukan analisis multivariat regresi logistik, yaitu pada kelompok usia, frekuensi, dan durasi mondok. Sementara pada Tabel 4 didapatkan hasil analisis bivariat faktor yang memengaruhi skor peer problems terhadap kelompok $\mathrm{SN}, \mathrm{KrS}$, dan KrNS yang bermakna adalah frekuensi mondok dan durasi mondok. Analisis regresi logistik juga dilakukan pada faktor yang memiliki $\mathrm{p}<0,25$, yaitu jenis kelamin dan pendidikan ibu.

Hasil multivariat dosis kumulatif steroid yang tinggi atau lebih dari $7200 \mathrm{mg}$ secara signifikan berpengaruh lebih sering mengalami gangguan perilaku 11,64 
Diarum Puspasari dkk: Kecenderungan gangguan perilaku dengan SN

Tabel 4. Analisis bivariat faktor yang berpengaruh pada kejadian peer problems kelompok SN, KrS, dan KrNS

\begin{tabular}{|c|c|c|c|c|c|}
\hline \multirow[b]{2}{*}{ Variabel } & \multicolumn{2}{|c|}{ Peer problems } & \multirow[b]{2}{*}{$\mathrm{RP}$} & \multirow[b]{2}{*}{ IK95\% } & \multirow[b]{2}{*}{$\mathrm{p}$} \\
\hline & $\begin{array}{c}\mathrm{Ya} \\
\mathrm{N}=99(\%)\end{array}$ & $\begin{array}{c}\text { Tidak } \\
\mathrm{N}=99(\%)\end{array}$ & & & \\
\hline \multicolumn{6}{|l|}{ Usia } \\
\hline 3-10 tahun(anak) & $9(9,1)$ & $60(60,6)$ & 0,97 & $0,27-3,45$ & $1,00^{\mathrm{a}}$ \\
\hline 11-16 tahun(remaja) & $4(4)$ & $26(26,3)$ & & & \\
\hline \multicolumn{6}{|l|}{ Jenis kelamin } \\
\hline Laki-laki & $10(10,1)$ & $49(49,5)$ & 2,51 & $0,65-9,79$ & $0,17^{\mathrm{a} *}$ \\
\hline Perempuan & $3(3,0)$ & $37(37,4)$ & & & \\
\hline \multicolumn{6}{|l|}{ Pendidikan ibu } \\
\hline Rendah & $9(9,1)$ & $36(36,4)$ & 3,12 & $0,89-10,94$ & $0,059^{a *}$ \\
\hline Tinggi & $4(4)$ & $50(50,5)$ & & & \\
\hline \multicolumn{6}{|l|}{ Sosial ekonomi } \\
\hline Rendah & $4(4)$ & $28(28,3)$ & 0,92 & $0,26-3,25$ & $1,00^{\mathrm{b}}$ \\
\hline Menengah-ke atas & $9(9,1)$ & $58(58,6)$ & & & \\
\hline \multicolumn{6}{|l|}{ Usia onset (tahun) } \\
\hline$<3$ & $4(4)$ & $29(29,3)$ & 0,87 & $0,25-3,07$ & $1,00^{\mathrm{b}}$ \\
\hline$\geq 3$ & $9(9,1)$ & $57(57,6)$ & & & \\
\hline \multicolumn{6}{|l|}{ Durasi sakit (tahun) } \\
\hline$\geq 3$ & $8(8,1)$ & $45(45,5)$ & 1,45 & $0,44-4,81$ & $0,53^{a}$ \\
\hline$<3$ & $5(5,1)$ & $41(41,4)$ & & & \\
\hline \multicolumn{6}{|l|}{ Frekuensi rawat (kali) } \\
\hline$>2$ & $7(7,1)$ & $15(15,2)$ & 5,52 & $1,62-18,78$ & $0,008^{\mathrm{b} *}$ \\
\hline$\leq 2$ & $6(6,1)$ & $71(71,7)$ & & & \\
\hline \multicolumn{6}{|l|}{ Durasi rawat (hari) } \\
\hline$>14$ & $9(9,1)$ & $32(32,3)$ & 3,79 & $1,08-13,33$ & $0,02^{\mathrm{a} *}$ \\
\hline$\leq 14$ & $4(4,1)$ & $54(54,5)$ & & & \\
\hline
\end{tabular}

Keterangan: p dianggap bermakna apabila nilai $\mathrm{p}<0,05,{ }^{\mathrm{a}}$ chi square, ${ }^{\mathrm{b}} \mathrm{uji}$ Fisher, ${ }^{*} \mathrm{p}<0,25$

Tabel 5. Analisis multivariat faktor yang berpengaruh terhadap kejadian gangguan perilaku kelompok SN dibandingkan kelompok $\mathrm{KrS}$ dan KrNS

\begin{tabular}{lcccccc}
\hline \multirow{2}{*}{ Variabel } & \multicolumn{7}{c}{ Analisis multivariat } \\
\cline { 2 - 7 } & \multicolumn{7}{c}{ Kelompok SN dibandingkan KrS } & \multicolumn{3}{c}{ Kelompok SN dibandingkan KrNS } \\
\cline { 2 - 7 } & OR & IK95\% & p & OR & IK95\% & $\mathrm{p}$ \\
\hline Penyakit SN & 1,09 & $0,08-14,34$ & 0,94 & 3,49 & $0,32-37,38$ & 0,30 \\
Kelompok usia 3-10 tahun & 7,69 & $1,03-57,53$ & 0,47 & 22,87 & $1,90-274,71$ & $0,01^{*}$ \\
Jenis kelamin laki-laki & 9,38 & $0,00-$ & 0,99 & 25,01 & $2,21-282,02$ & $0,009^{*}$ \\
Frekuensi rawat inap >2 kali & 1,88 & $0,23-14,81$ & 0,54 & 10,08 & $1,70-59,65$ & $0,01^{*}$ \\
Durasi rawat inap >14 hari & 1,76 & $0,21-14,58$ & 0,59 & 0,72 & $0,09-5,45$ & 0,75 \\
Dosis steroid >7200 mg & 11,64 & $2,33-58,06$ & $0,003^{*}$ & - & - & - \\
\hline
\end{tabular}

Keterangan: *p dianggap bermakna apabila nilai $\mathrm{p}<0,05$

kali (IK95\% 2,33-58,06; p=0,003) pada kelompok SN dan KrS (Tabel 5).

Pada analisis multivariat kelompok SN terhadap KrNS, disimpulkan bahwa kelompok usia 3-10 tahun memiliki risiko lebih banyak mengalami gangguan perilaku 22,87 kali (IK95\% 1,90-274,71; p=0,01), jenis kelamin laki-laki memiliki risiko terjadinya gangguan perilaku 25,01 kali lebih sering (IK95\% 
2,21-282,02; $\mathrm{p}=0,009)$, frekuensi rawat inap lebih dari 2 kali memiliki risiko 10,08 kali (IK95\% 1,70-59,65; $\mathrm{p}=0,01)$ (Tabel 5).

Hasil analisis multivariat pada kelompok SN dan KrNS yang bermakna secara statistik adalah penyakit SN lebih sering memiliki risiko 12 kali terjadinya peer problems dibandingkan anak dengan KrNS (IK95\% 1,42-101,25; $\mathrm{p}=0,02$ ) (Tabel 6). Selain itu, hasil frekuensi mondok lebih dari 2 kali juga memiliki risiko prevalensi lebih tinggi 4,9 kali terjadinya peer problems dibandingkan anak dengan kelompok $\mathrm{SN}$ dan $\mathrm{KrS}$ (IK95\% 1,31-18,24; p=0,01). tinggi pada kelompok SN dibandingkan kelompok KrS dan KrNS, walaupun perbedaan tersebut secara statistik tidak bermakna. Laporan penelitian sebelumnya juga mendapatkan bahwa masalah internalisasi, seperti menarik diri dari pergaulan sosial atau peer problems juga didapatkan prevalensi yang lebih banyak pada anak SN.4,8,11 Gangguan hubungan sosial dengan teman sebaya terjadi pada anak dengan penyakit kronis termasuk SN karena rasa ketergantungan terhadap orang tua akan meningkat serta sering mengganggu aktivitas sekolah serta aktivitas sehari-hari anak sehingga mengakibatkan anak tersisihkan dari aktivitas

Tabel 6. Analisis multivariat faktor yang berpengaruh terhadap kejadian peer problems kelompok SN dibandingkan kelompok KrS dan KrNS

\begin{tabular}{lcccccc}
\hline \multirow{2}{*}{ Variabel } & \multicolumn{3}{c}{ Analisis multivariat } & \multicolumn{3}{c}{ Analisis multivariat } \\
& \multicolumn{2}{c}{ Kelompok SN dibandingkan KrS } & \multicolumn{2}{c}{ Kelompok SN dibandingkan KrNS } \\
\cline { 2 - 7 } & OR & IK95\% & $\mathrm{p}$ & OR & IK95\% & $\mathrm{p}$ \\
\hline Penyakit SN & 1,23 & $0,18-8,28$ & 0,83 & 12 & $1,42-101,25$ & $0,02^{*}$ \\
Durasi rawat >14 hari & 1,74 & $0,44-6,94$ & 0,42 & 2,69 & $0,24-29,26$ & 0,41 \\
Jenis kelamin laki-laki & 2,35 & $0,42-12,97$ & 0,32 & 0,71 & $0,11-4,42$ & 0,72 \\
Tingkat pendidikan ibu rendah & 2,5 & $0,62-10,05$ & 0,19 & 1,43 & $0,28-7,22$ & 0,66 \\
Frekuensi mondok >2 kali & 4,9 & $1,31-18,24$ & $0,01^{*}$ & 3,41 & $0,68-17,05$ & 0,13 \\
\hline
\end{tabular}

Keterangan:* p dianggap bermakna apabila nilai $\mathrm{p}<0,05$

\section{Pembahasan}

Penyakit kronis memiliki dampak psikologis yang besar terhadap perkembangan anak. Prevalensi gangguan perilaku penelitian ini lebih tinggi 36,4\% pada kelompok SN dibandingkan kedua kelompok pembandingnya, sesuai laporan penelitian sebelumnya oleh Manti dkk ${ }^{4}(32,1 \%)$. Namun, prevalensi ini lebih rendah dibandingkan beberapa penelitian sebelumnya yang mencapai $60 \%$ sampai dengan $68 \%$. Hal tersebut disebabkan karena dilakukan pada kelompok yang sebagian besar status ekonominya rendah. Sebaliknya, kelompok SN penelitian kami lebih banyak berada pada status sosial menengah tinggi. ${ }^{2,8,9}$ Prevalensi SN lebih tinggi dibandingkan kelompok pembandingnya sesuai dengan yang didapat pada beberapa penelitian sebelumnya. , $^{2,8-810}$

Selain gangguan perilaku, prevalensi hasil skor abnormal untuk kelompok SN pada peer problems juga lebih tinggi daripada kelompok $\mathrm{KrS}$ dan $\mathrm{KrNS}$ $(27,3 \%)$. Hasil yang sama juga kami dapatkan untuk gangguan hiperaktif dengan persentase yang lebih sosial dan pergaulan teman sebayanya. ${ }^{11}$

Terkadang, orang tua terlalu melindungi atau overprotective terhadap anaknya, seperti membatasi interaksi dengan teman untuk mengurangi risiko infeksi sehingga anak malu dengan kondisinya dan menarik diri dari lingkungan pergaulan dengan teman sebayanya. ${ }^{4}$ Selain akibat perilaku orang tua, ketidakhadiran di sekolah untuk keperluan kontrol dan mondok di rumah sakit juga dapat menyebabkan anak SN menarik diri dari pergaulan dan kehidupan sosialnya. Perubahan fisik akibat terapi penggunaan steroid yang dapat menyebabkan obesitas dan hirurstism menyebabkan anak malu untuk menemui teman-temannya dan merasa terisolasi dari pergaulan teman sebayanya ${ }^{2,5,10}$

Gangguan pada anak SN masih sulit dibedakan, apakah penyebab gangguan akibat penyakitnya atau pengobatannya. Sebagai salah penyakit kronik, SN juga akan berdampak sosial serta kondisi psikologis pada anak yang menderita. ${ }^{11}$ Pada perbandingan SN dengan $\mathrm{KrS}$, kedua kelompok tersebut menggunakan steroid sebagai terapi, diperoleh gangguan perilaku 
yang lebih banyak dialami pada SN hanya pada aspek gangguan perilaku total $(36,4 \%$ vs $9,1 \%)$, hiperaktif ( $21,2 \%$ vs $6,1 \%)$, dan peer problems $(27,3 \%$ vs $9,1 \%)$ dengan hasil yang bermakna hanya pada gangguan perilaku secara total. Sebaliknya, pada perbandingan kelompok SN dengan KrNS, hanya pada kelompok SN saja yang menggunakan terapi steroid. Gangguan perilaku atau hasil yang abnormal didapatkan lebih tinggi pada semua aspek di kelompok SN, yaitu aspek gangguan perilaku total $(36,4 \%$ vs $3 \%)$, hiperaktif ( $21,2 \%$ vs $6,1 \%)$, conduct problem $(18,2 \%$ vs $6,1 \%)$, emosi $(24,2 \%$ vs $21,2 \%)$, peer problems ( $27,3 \%$ vs $3 \%)$, dan prososial abnormal (6,1\% vs $0 \%)$ dengan hasil statistik yang bermakna hanya pada gangguan perilaku total serta peer problems. Hal tersebut menggambarkan bahwa pengobatan steroid memberikan efek terjadinya gangguan perilaku. ${ }^{4,5}$

Faktor yang memengaruhi gangguan perilaku pada kelompok $\mathrm{SN}$ dan $\mathrm{KrS}$ adalah dosis kumulatif steroid yang lebih dari $7200 \mathrm{mg}$, sedangkan dari penyakitnya sendiri tidak bermakna. Soliday dkk, ${ }^{5}$ Hall dkk dan Mishra $\mathrm{dkk}^{11}$ juga mendapatkan hasil yang konsisten bahwa akumulasi dosis prednison merupakan prediktor kuat terjadinya gangguan perilaku. Sebaliknya, Guha $\mathrm{dkk}^{2}$ mendapatkan hasil yang berlawanan bahwa steroid tidak menyebabkan gangguan perilaku pada $66 \%$ pasien $\mathrm{SN}$ yang dalam terapi steroid. Hal tersebut terjadi akibat dosis steroid yang diberikan saat itu dalam dosis yang rendah. Selain itu, faktor yang memengaruhi gangguan perilaku dan peer problems adalah frekuensi mondok lebih dari dua kali, usia yang lebih muda, dan penyakit SN. Usia muda di bawah 10 tahun juga merupakan faktor yang memengaruhi gangguan perilaku pada pasien $\mathrm{SN}$ sensitif steroid pada penelitian Soliday dkk, ${ }^{9}$ tetapi berbeda dengan hasil penelitian Boraey $\mathrm{dkk}^{8}$ yang melaporkan bahwa usia lebih dari 10 tahun merupakan faktor yang memengaruhi terjadinya gangguan psikososial.

Frekuensi rawat inap yang sering untuk pengobatan SN menyebabkan waktu dan kesempatan anak untuk bersosialisasi dengan teman sebayanya berkurang. Frekuensi rawat inap di rumah sakit, walaupun dalam jangka waktu yang pendek, dapat menyebabkan efek samping yang tidak menyenangkan pada anak karena memberikan paparan terhadap beberapa stressor, termasuk berpisah dengan anggota keluarga, teman dan lingkungan sekolah, adaptasi terhadap suasana lingkungan rumah sakit, nyeri akibat terapi, dan ketakutan akan ketidakpastian. ${ }^{10,12}$
Penelitian ini merupakan penelitian potong lintang sehingga memiliki kekurangan untuk menganalisis hubungan sebab akibat sehingga memerlukan penelitian lebih lanjut dengan menggunakan metode penelitian prospektif.

\section{Kesimpulan}

Prevalensi gangguan perilaku dan peer problems didapatkan lebih banyak terjadi pada SN dibanding penyakit kronis lain dengan terapi steroid maupun tidak. Namun, faktor yang berpengaruh pada gangguan tersebut lebih disebabkan karena dosis kumulatif steroid yang tinggi, frekuensi mondok lebih dari dua kali, dan usia lebih muda dibandingkan akibat penyakit $\mathrm{SN}$ itu sendiri.

\section{Daftar pustaka}

1. Alatas H, Tambunan T, Trihono PP, Pardede SO. Konsensus Tata Laksana Sindrom Nefrotik Idiopatik pada Anak. Unit Kerja Koordinasi Nefrologi IDAI; 2005.

2. Guha P, De A, Ghosal M. Behaviour profile of children with nephrotic syndrome. Indian J Psychiatry 2009;51:122-6.

3. Ghobrial EE, Fahmey SS, Ahmed ME, Botrous OE. Behavioral changes in Egyptian children with nephrotic syndrome. IJKD 2013;7:108-16.

4. Manti P, Giannakopoulos G, Giouroukou E, GeorgakiAngelaki H, Stefanidis C, Mitsioni A, dkk. Psychosocial and cognitive function in children with nephrotic syndrome: association with disease and treatment variables. Bio Psycho Soc Med 2013;7:1-7.

5. Mishra OP, Basu B, Upadhyay SK, Prasad R, Schaefer F. Behavioral abnormalities in children with nephrotic syndrome. Nephrol Dial Transplant 2010;6:1-5.

6. Goodman R, Scoot S. Comparing the Strength and Difficulties Questionnaire and the Child Behavior Checklist: Is small beautiful? J Abnormal Child Psychol 1999;27:17-24.

7. International Study of Kidney Disease in Children. The primary nephrotic syndrome in children. Identification of patients with minimal change nephrotic syndrome from initial response to prednisone. A report of the International Study of Kidney Disease in Children. J Pediatr 1981;98:561-4. 
8. Boraey NF, Sobaty MME. Behavioral problems in children with nephrotic syndrome. Appl Sci Res 2011;7:2001-7.

9. Soliday E, Grey S, Lande MB. Behavioral effects of corticosteroid in steroid sensitive nephrotic syndrome. Pediatrics 1999;10:1-4.

10. Mehta M, Bagga A, Pande P, Bajaj C, Srivastava RN.
Behavior problem in nephrotic syndrome. Indian Pediatrics 1995;32:1281-6.

11. Hall AS, Thorley G, Houtman PN. The effects of corticosteroids on behavior in children with nephrotic syndrome. Pediatr Nephro 2003;18:1220-3.

12. Pao M, Ballard ED, Rosenstein DL. Growing up in the hospital. J Am Med Assoc 2007;292:2752-5. 